\title{
CYTOTOXIC CONSTITUENTS FROM THE ROOT WOOD OF FORMOSAN MICHELIA COMPRESSA
}

\author{
CHIA-YUAN LIU ${ }^{1,3,6}$, YANG-WEN CHEN ${ }^{4,6}$, MING-JEN CHENG ${ }^{4,6,7}$, SHOIW-JU LEE ${ }^{5}$, MOHAMED H. ABD EL- \\ RAZEK ${ }^{4}$, WEN-HSIUNG CHANG ${ }^{1}$, YU-JEN CHEN ${ }^{2}$, AND IH-SHENG CHEN ${ }^{4 *}$ \\ ${ }^{l}$ Division of Gastroenterology, Department of Internal Medicine, Mackay Memorial Hospital, Taipei, Taiwan, R.O.C. \\ ${ }^{2}$ Department of Radiation Oncology, Mackay Memorial Hospital, Taipei, Taiwan, R.O.C. \\ ${ }^{3}$ Institute of Traditional Medicine, National Yang-Ming University, Taipei, Taiwan, R.O.C. \\ ${ }^{4}$ Graduate Institute of Natural Products, College of Pharmacy, Kaohsiung Medical University, Kaohsiung, Taiwan, R.O.C. \\ ${ }_{5}^{5}$ Department of Biotechnology and Pharmaceutical Research, National Health Research Institutes (NHRI), Miaoli County, Taiwan, R.O.C. \\ ${ }^{6}$ These authors contributed equally to the manuscript. \\ ${ }^{7}$ Present address: Bioresource Collection and Research Center, Food Industry Research and Development Institute. Hsinchu, Taiwan, R.O.C. \\ Correspondence: Professor I.S. Chen Ph, D. School of Pharmacy, College of Pharmacy, Kaohsing Medical University, Kaohsiung, Taiwan, R.O.C. \\ (Received: 12 April 2007 - Accepted: 12 March 2008)
}

\begin{abstract}
The methanolic extract of the root wood of Michelia compressa (Maxim.) Sargent showed cytotoxicity against MCF-7, NCI-H460 and SF-268 cancer cell lines. Bioassay-guided fractionation of the chloroform-soluble layer led to the isolation of costunolide and liriodenine with cytotoxic activities, along with the isolation of twenty-seven known compounds. The active costunolide existed as major constituent in this study.
\end{abstract}

Keywords: Michelia compressa, Magnoliaceae, root wood, cytotoxicity

\section{INTRODUCTION}

Michelia species have been used as folk medicine in the treatment of cancer $^{1}$. In a screening program of Formasan plants for cytotoxic activity against MCF-7, NCI-H460 and SF-268 cancer cell lines, Michelia compressa (Maxim.) Sargent (M. formosana (Kaneh.) Masam. \& Suzuki, Magnolia compressa Maxim.) (Magnoliaceae) was found to be one of the active species. $M$. compressa is an evergreen tree distributed in Japan, Ryukyu Island and Taiwan $^{2}$. Its heart wood with high decay resistance against rots due to the presence of liriodenine ${ }^{3}$. The chemical investigation of leaves ${ }^{4}$, bark ${ }^{5}$, root bark $^{6}$, heart wood ${ }^{7,8}$ stem $^{9}$, pericarp ${ }^{10}$ have been studies, but the chemical and cytotoxic constituents of the root wood were still not conducted. Bioassayguided fractionation of the $\mathrm{CHCl}_{3}$-soluble layer of the root wood has led to the isolation of costunolide (1) and liriodenine (11) with cytotoxic activities, along with the isolation of twenty-five inactive known compounds. The isolation and the cytotoxic properties of the isolates are described herein.

\section{EXPERIMENTAL}

\section{General experimental procedures}

Melting points were determined with a YANACO micro-melting point apparatus and were uncorrected. IR spectra were taken on a Hitachi 26030 spectrophotometer. UV spectra were obtained on a JASCO UV-240 spectrophotometer. EIMS spectra were recorded on a VG Biotech Quattro 5022 spectrometer. HREIMS were recorded on a JEOL JMX-HX 110 mass spectrometer. ${ }^{1} \mathrm{H}$ NMR and ${ }^{13} \mathrm{C}$ NMR spectra were measured on a Varian Gemini 200, and Varian Unity Plus 400 spectrometers, and are given in parts per million $(\delta)$ downfield from internal TMS. Si gel 60 (Merck 70-230 mesh, 230-400 mesh) was used for column chromatography, and Si gel $60 \mathrm{~F}_{254}$ (Merck) for TLC.

\section{Plant material}

The root wood of M. compressa was collected from Lai-I, Pingtung County, Taiwan, in July, 2004, and identified by Prof. I. S. Chen. A voucher specimen (Chen 5443) was deposited in the herbarium of the College of Pharmacy, Kaohsiung University, Kaohsiung, Taiwan.

\section{Cytotoxicity assay}

Human MCF-7 cells (breast cancer), NCI-H460 cells (lung cancer), and SF268 cells (central nervous cancer) were cultured in Dulbecco's modified Eagle's medium supplemented with $10 \%$ fetal calf serum and nonessential amino acid (Life Technologies, Inc.) and maintained at $37^{\circ} \mathrm{C}$ in a humidified incubator with $5 \% \mathrm{CO}_{2}$. Human cancer cells were seeded in 96 -well microtiter plates at a density of $6000 /$ well in $100 \mu \mathrm{l}$ culture medium. After an overnight adaptation period, $50 \mu \mathrm{g} / \mathrm{ml}$ (final concentration) of test compounds in serum-free medium were added to individual wells. Cells were treated with test compounds for 3 days. Cell viability was determined by the 5-(3-carboxymethoxyphenyl)-2- (4,5-dimethylthiazoyl)- 3-(4-sulfophenyl) tetrazolium salt (MTS) reduction assay. Actinomycin D $5 \mu \mathrm{M}$ (final concentration) and DMSO $0.3 \%$ (final concentration) were used as positive and vehicle controls. Results were expressed as a percentage of DMSO control ${ }^{11}$.

\section{Extraction and separation of compounds}

The dried root wood $(14.2 \mathrm{~kg})$ was extracted with cold $\mathrm{MeOH}$, and the extract was concentrated under reduced pressure. The $\mathrm{MeOH}$ extract $(600 \mathrm{~g})$ was partitioned between $\mathrm{H}_{2} \mathrm{O}-\mathrm{CHCl}_{3}(1: 1)$ to give the $\mathrm{CHCl}_{3}$-soluble fraction (Fr. A, 280 g). The $\mathrm{H}_{2} \mathrm{O}$ solution was partitioned between EtOAc- $\mathrm{H}_{2} \mathrm{O}(1: 1)$ to give EtOAc-soluble fraction (Fr. $\mathrm{B}, 13 \mathrm{~g}$ ). The $\mathrm{H}_{2} \mathrm{O}$ solution was partitioned between $n-\mathrm{BuOH}_{-} \mathrm{H}_{2} \mathrm{O}(1: 1)$ to give $n$ - $\mathrm{BuOH}$-soluble fraction (Fr. C, $84 \mathrm{~g}$ ), and $\mathrm{H}_{2} \mathrm{O}$-soluble fraction (Fr. D, $\left.192 \mathrm{~g}\right)$. Fraction A (100 g) was chromatographed on Si gel and eluted with $n$-hexane, and the polarity was gradually increased with EtOAc and $\mathrm{MeOH}$ to furnish 12 fractions (A-1 to A-12). Fr. A-4 (26.46 g) was washed with $\mathrm{MeOH}$ to give costunolide (1) (11.51 g). Part (200 mg) of the washing $(13.67 \mathrm{~g})$ was puritified by HPLC, eluting with $n$-hexaneEtOAc (4:1) to afford arbusculin A (6) (25 mg). Fraction A-7 (4.23 g) was subjected to Sephadex LH-20 and eluted with $\mathrm{MeOH}$ to give 6 fractions (A7-1 to A-7-6). Fraction A -7-3 (8.2 mg)was purified by preparative TLC to produce (-)- $N$-formyldehydro- anonaine (12) $(1.3 \mathrm{mg})$. Fraction A-8 (4.02 g) was subjected to Sephadex LH-20 and eluted with $\mathrm{MeOH}$ to give a mixture

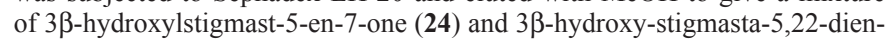
7-one $(\mathbf{2 5})(6.3 \mathrm{mg})$, a mixture of $6 \beta$-hydroxystigmast- 4 -en-3-one $(\mathbf{2 6})$ and 63-hydroxystigmasta-4,22-dien-3-one (27) (7.3 mg). Fraction A-9 (4.09 g) was subjected to Si gel and eluted with $\mathrm{CHCl}_{3}$, and then enriched with EtOAc to give santamarin (2) (13.3 mg), reynosin (3) (16.9 mg), (-)- $N$-formylanonaine (9) $(3.3 \mathrm{mg})$, artabonatine A (13) $(1.1 \mathrm{mg})$, and syringaldehyde $(\mathbf{2 3})(6.3 \mathrm{mg})$ Fraction A-10 (11.69 g) was subjected to Si gel chromatography and eluted with $\mathrm{CH}_{2} \mathrm{Cl}_{2}$-acetone step gradients to give (-)- $\mathrm{N}$-acetylanonaine (7) (2.7 $\mathrm{mg})$. Fraction $11(9.28 \mathrm{~g})$ was subjected to Sephadex LH-20, and eluted with $\mathrm{MeOH}$ to give (-)-T-cadinol (5) (3.4 mg), (-)- $N$-acetylnornuciferine (8) $(2.2$ $\mathrm{mg}), N$-trans-feruloyltyramine (14) $(4.3 \mathrm{mg}), N$-cis-feruloyltyramine (15) $(1.7$ $\mathrm{mg}), \mathrm{N}$-trans-feruloylmethoxytyramine (16) (4.3 mg), $\mathrm{N}$-cis-feruloylmethoxytyramine (17) $(1.4 \mathrm{mg}),(+)-5,5^{\prime}$-dimethoxylariciresinol (18) $(3.3 \mathrm{mg}),(+)-$ 5-methoxylariciresinol (19) (1.9 mg), (+)-lariciresinol (20) (2.1 mg), ( \pm )syringaresinol (21) (113 mg), 1,2-bis-(4-hydroxy-3-methoxyphenyl)-1,3ropane- diol (22) (3.4 mg). Fraction $12(10.91 \mathrm{~g})$ was subjected to Sephadex LH-20, and eluted with $\mathrm{MeOH}$ to give parthenolide (4) (18 mg), (-)-romucosine (10) (10.4 mg), and liriodenine (11) (13 mg).

\section{Spectroscopic data}

costunolide (1): all spectroscopic data accord with ref. 6. santamarin (2): all spectroscopic data accord with ref. 6. parthenolide (4): all spectroscopic data accord with ref. 6. liriodenine (11): all spectroscopic data accord with ref. 6. 


\section{RESULTS AND DISCUSSION}

The EtOAc-soluble fraction of the methanol extract was fractionated by a combination of silica gel, Sephadex LH-20, and prep. TLC to yield 27 compounds, their structures were elucidated by 1D and 2D NMR spectra and comparison with literature data. Amomg above isolates, costunolide (1) was the major constituent from this study, and was also previously isolated from the root bark of the same plant by Ogura et al. $(1978)^{6}$. From this study, we can reveal costunolide also exists in root wood as a major composition.

The cytotoxic effects of the isolates from the root wood of $M$. compressa were tested in vitro against MCF-7, NCI-H460 and SF-268 cancer cell lines. The cytotoxic data are shown in Table 1 . The clinically used anticancer agent, mithramycin, was used as positive control. As can been shown from Table 1 , compounds $2-4,6$, and 10 showed no cytotoxic activities, and the major constituent $\mathbf{1}$ and $\mathbf{1 1}$ were only shown weakly active.

From the results of the cytotoxic tests, the following conclusions can be drawn regarding these isolates: (a) Among the sesquiterpenes, only costunolide (1) as major constituent, showed marginal cytotoxicity against these three cancer cell lines. Comparing the cytotoxicities of costunolide (1), santamarin (2), and parthenolide (4), to the previous cytotoxic data of these three compounds on $\mathrm{KB}\left(\mathrm{IC}_{50}=0.69,1.1 \text {, and } 0.45 \mu \mathrm{g} / \mathrm{ml}\right)^{6}$ revealed that $\mathrm{KB}$ cell is more susceptible to these three compounds than MCF-7, NCI-H460, and SF-268 cell. (b) The aporphine, liriodenine (11) exhibited significant cytotoxic activity against these three cancer cell lines. This compound also can inhibit the proliferation of human hepatoma cell lines ${ }^{12}$. (c) Costunolide (1) exhibited more cytotoxic than parthenolide (4), and this revealed that epoxidation of the C-4,5 bond of 4 would result in reduced of cytotoxicity activity. Another known compound, $N$ trans-feruloylmethoxytyramine (14) with cytotoxicity against P-388 and HL60 cancer cell lines was already reported ${ }^{13}$.
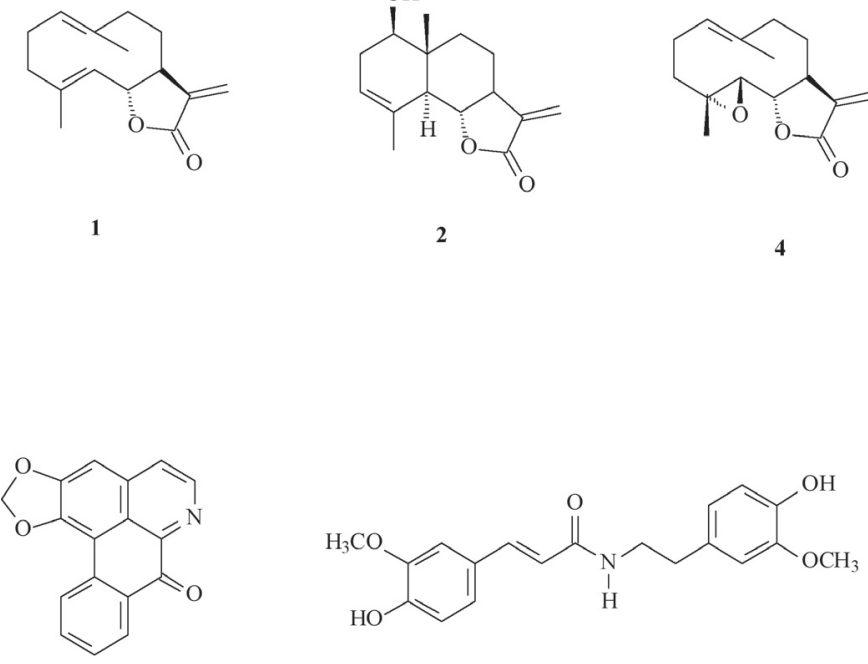

11

14

Table. 1 Cytotoxic effects of compounds isolated from the root wood of Michelia compressa against MCF-7, NCI-H460 and SF268 cell lines

\begin{tabular}{llll}
\hline & \multicolumn{3}{c}{$\mathrm{IC}_{50}(\mu \mathrm{g} / \mathrm{ml})$} \\
\hline Compounds & MCF-7 & NCI-H460 & SF-268 \\
& & & \\
Costunolide (1) & 5.26 & 6.95 & 5.31 \\
Santamarin (2) & 17.42 & 15.18 & 10.48 \\
Reynosin (3) & 10.93 & 13.96 & 10.76 \\
Parthenolide (4) & $>50$ & $>50$ & $>50$ \\
T-Cadinol (6) & $>50$ & $>50$ & $>50$ \\
(-)-Romucosine (10) & $>50$ & $>50$ & $>50$ \\
Liriodenine (11) & 2.75 & 3.21 & 3.22 \\
\hline
\end{tabular}

a Positive control : Actinomycin D

${ }^{\mathrm{b}}$ For significant activity of pure compound an $\mathrm{IC}_{50} \leq 4.0 \mu \mathrm{g} / \mathrm{ml}$ is required.
The known isolates including six sesquiterpenes, costunolide $(\mathbf{1})^{6}$, santamarin (2) ${ }^{6}$, reynosin $(3)^{6}$, parthenolide $(4)^{6},(-)$-T-cadinol $(5)^{14}$ and arbusculin A (6) ${ }^{15}$; seven alkaloids, (-)- $N$-acetylanonaine $(7)^{16},(-)-N$ acetylnornuciferine $(\mathbf{8})^{16},(-)-N$-formylanonaine $(\mathbf{9})^{17},(-)$-romucosine $(\mathbf{1 0})^{18}$, liriodenine $(\mathbf{1 1})^{9},(-)-N$-formyldehydroanonaine $(\mathbf{1 2})^{19}$ and artabonatine $\mathrm{A}$ $(\mathbf{1 3})^{20}$; four amides, $N$-trans-feruloyltyramine $(\mathbf{1 4})^{9}, \mathrm{~N}$-cis-feruloyltyramine $(\mathbf{1 5})^{9}, N$-trans-feruloylmethoxytyramine $(\mathbf{1 6})^{21}$ and $N$-cis-feruloylmethoxytyramine $(\mathbf{1 7})^{21}$; five lignans, (+)-5,5'-dimethoxylariciresinol (18 $)^{22},(+)$ 5-methoxylariciresinol $\quad(\mathbf{1 9})^{23}, \quad(+)$-lariciresinol $\quad(\mathbf{2 0})^{22}, \quad( \pm)$-syringaresinol $(\mathbf{2 1})^{9}$ and 1,2-bis-(4-hydroxy-3-methoxyphenyl)-1,3-ropanediol (22) ${ }^{24}$; one

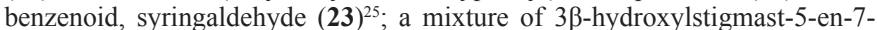
one (24) and $3 \beta$-hydroxy-stigmasta-5,22-dien-7-one $(\mathbf{2 5})^{26}$, a mixture of $6 \beta$ hydroxystigmast-4-en-3-one (26) and 6 $\beta$-hydroxystigmasta-4,22-dien-3-one $(\mathbf{2 7})^{27}$, were identified by comparison of physical and spectroscopic data (UV, IR, ${ }^{1} \mathrm{H}-\mathrm{NMR},[\alpha]_{\mathrm{D}}$, and Mass spectroscopic data) to corresponding authentic samples or literature values. Among the isolates, 16 compounds $(\mathbf{5}, \mathbf{6 , 1 0 , 1 2}$, 13, 16-20, 22-27) were first isolated from this species.

\section{ACKNOWLEDGEMENTS}

This work was generously supported by Mackay Memorial Hospital, Taipei, Taiwan.

\section{REFERENCES}

1. J. L. Hartwell, Lloydia 33, 97, (1970).

2. H. Keng, Magnoliaceae in Flora of Taiwan, $2^{\circ}$ Ed., Editorial Committee of the Flora of Taiwan, Taipei, Vol.II, 1996; pp. 410-4.

3. C. C. Wu, Master Thesis: Study on antifungal compounds of Michelia formosana, School of Forestry and Resource Conversion, National Taiwan University, 2006.

4. T. Koyama, T. Morikita, Chem. Pharm. Bull. 69, (1955).

5. K. Ito, Yakugaku Zasshi 80, 705, (1960).

6. M. Ogura, G. A. Cordell, N. R. Farnsworth, Phytochemistry 17, 957, (1978).

7. M. Tomita, H. Fukukawa, Yakugaku Zasshi 82, 925, (1962).

8. T. H. Yang, Yakugaku Zasshi 82, 794, (1962).

9. W. L. Lo, Y. C. Wu, T. J. Hsieh, S. H. Kuo, Chin. Pharm. J. 56, 69, (2004).

10. L. C. Lo, Ph. D. Thesis: Studies on the constituents of the parasitic plants (Aeginetia indica, Cassytha filiformis) and Chinese Medicines (Tetrapanax papyriferus, Michelia compressa) in Taiwan. Department of Chemistry, National Tsing Hua University, Taiwan, 1999.

11. D. Sladowski, S. Steer, R. H. Clothier, M. Balls, I. Chihiro, J Immunol. Methods 157, 203, (1993).

12. T. J. Hsieh, T. Z. Liu, C. L. Chern, D. A. Tsao, F. J. Lu, Y. H. Syu, P. Y. Hsieh, H. S. Hu, T. T. Chang, C. H. Chen, Food Chem. Toxicol. 43, 1117, (2005).

13. Y. C. Wu, G. Y. Chang, F. N. Ko, Planta Medica 61, 146, (1996).

14. C. Labbe, M. Castillo, J. D. Connolly, Phytochemistry 34, 441, (1993).

15. I. G. Collado, J. G. Madero, G. M. Massanet, F. R. Luis, J. Org. Chem. 56, 3587, (1991).

16. C. D. Hufford, Phytochemistry 15, 1169, (1976).

17. F. R. Chang, C. Y. Chen, T. J. Hsieh, C. P. Cho, Y. C.Wu, J. Chin. Chem. Soc. 47, 913, (2000).

18. Y. Y. Chen, F. R. Chang, Y. C. Wu, J. Nat. Prod. 59, 904, (1996).

19. M. D. Menachery, G. W. Blake, C. Beiswenger, A. Freyer, Heterocycles 41, 1425, (1995).

20. T. J. Hsieh, C. Y. Chen, R. Y. Kuo, F. R. Chang, Y. C. Wu, J. Nat. Prod. 62, 1192, (1999).

21. C. Y. Chen, F. R. Chang, H. F. Yen, Y. C. Wu, Phytochemistry 49, 1443, (1998).

22. H. Achenbach, M. Stöcker, M. A. Constenla, Phytochemistry 27, 1835, (1988).

23. C. Rajendiran, B. R. Pai, P. S. Subramanian, Indian. J. Chem. 30B, 681, (1991).

24. K. Yoshikawa, N. Mimura, S. Arihara,. J. Nat. Prod. 61, 1137, (1998).

25. Y. Su, X. F. Ren, X. G. She, X. F. Pan, J. Chin. Chem. Soc. 51, 1333, (2004).

26. T. Katayama, L. B. Davin, A. Chu, N. G. Lewis, Phytochemistry 33, 581, (1993).

27. Y. Arai, T. Nakagawa, M. Hitosugi, K. Shiojima, H. Ageta, O. B. AbdelHalim, Phytochemistry 48, 471, (1998). 